\title{
Effect of ground tire rubber on structural, mechanical and thermal properties of flexible polyurethane foams
}

\author{
Łukasz Piszczyk • Aleksander Hejna • \\ Krzysztof Formela $\cdot$ Magdalena Danowska $\cdot$ \\ Michał Strankowski
}

Received: 23 June 2014 / Accepted: 19 December 2014 / Published online: 30 December 2014

(C) The Author(s) 2014. This article is published with open access at Springerlink.com

\begin{abstract}
Flexible polyurethane foams were modified with two kinds of ground tire rubber, untreated and thermomechanically reclaimed. A reclamation process was performed in auto-thermal conditions, which reduced the cost of the process and decreased the environmental impact of devulcanization (e.g., emission of gases). The reclamation process was carried out in a continuous manner using a corotating twin screw extruder. The foams were prepared by a single step method for the ratio of isocyanate groups to hydroxyl groups equals to one. The ground tire rubber particles were added to a polyol mixture. The impact of the rubber treatment on the properties of resulting polyurethane composites was determined by the analysis of static and dynamic mechanical properties and thermal properties. The incorporation of rubber particles into the polymer matrix caused significant changes in the cellular structure of polyurethane foam, which was confirmed by SEM images. Moreover, a higher content of ground tire rubber
\end{abstract}

Ł. Piszczyk · A. Hejna $(\varangle) \cdot$ K. Formela $\cdot$ M. Strankowski Department of Polymer Technology, Chemical Faculty, Gdansk University of Technology, G. Narutowicza Str. 11/12, 80-233 Gdansk, Poland

e-mail: aleksander.hejna@pg.gda.pl

Ł. Piszczyk

e-mail: lukpiszc@pg.gda.pl

K. Formela

e-mail: kformela.ktp@gmail.com

M. Strankowski

e-mail: michal.strankowski@pg.gda.pl

M. Danowska

Department of Solid State Physics, Faculty of Applied Physics and Mathematics, Gdansk University of Technology,

G. Narutowicza Str. 11/12, 80-233 Gdansk, Poland

e-mail: mdanowska@mif.pg.gda.pl in the polyurethane/ground tire rubber foamed composites enhanced their cross-link density estimated from the swelling measurements. It was also confirmed by an increase of glass transition temperature measured by dynamic mechanical analysis and differential scanning calorimetry. Addition of ground tire rubber to polyurethane foams had very positive influence on their thermal stability measured by the temperature corresponding to the $2 \%$ mass loss during degradation of material. Modification increased initial degradation temperature even by $14{ }^{\circ} \mathrm{C}$ compared to a reference sample.

Keywords Polyurethane foams - Ground tire rubber . Recycling · Waste rubber $\cdot$ Thermal properties

\section{Introduction}

Estimated data suggest that around the world over 17 million tons of waste tires is generated every year, of which nearly 3.3 million tons comes from the European Union (EU) [1]. Made from high-quality raw materials, waste tires and other rubber wastes are a very valuable source of secondary raw materials. The material recycling, still conducted only on a small scale, is a very good alternative for energy recovery. Incineration of waste tires, mainly in cement and power plants enables the recovery of only about $37 \%$ of energy used for the production of new tires [2]. Nowadays, industries and research centers in the EU and the whole world are searching for new, alternative and economically justified industrial scale methods of waste rubber recycling. Shredded rubber wastes have been used as fillers or substitutes of elastomers in rubber compounds, thermoplastic elastomers, thermoplastic compositions, epoxy resins, etc. [3-5]. A comprehensive review of the 
literature, on this subject, has been recently published by Karger-Kocsis et al. [6]. Waste rubber particles have been found to be valuable modifiers of asphalts and cements [79], and substrates in the processes of regeneration/devulcanization [10,11] and pyrolysis [12].

The cross-linked structure of shredded rubber waste has significant impact on the strength of interfacial interactions between rubber particles and polymer matrix. As an effect, the incorporation of big amounts of ground tire rubber (GTR) in polymer compositions results, in many cases, in worsening of mechanical properties. One of the possible solutions for the problem of weak adhesion of GTR to a polymer matrix is foaming of processing material [13].

Over the last few years, several research works [14-16] on the foamed polymer compositions containing rubber waste have been published. However, the main topic was the chemical foaming of polyolefin mixtures with waste rubber particles. An interesting alternative is foamed polyurethane (PUF) materials filled with ground tire rubber, whose properties can be changed, for example, by changing the chemical structure of polyurethane, type of modifiers (blowing agents, catalysts, surfactants), content of filler, etc.

The cross-linked structure of ground tire rubber in combination with the cellular structure of polyurethane matrix enables the application of prepared compositions as, among others, insulation materials, bumpers, damping materials and vibration absorbers.

Cachaço et al. [17] investigated the possibility of using polyurethane foams filled with GTR to produce floating trays and compression-absorbing buoys. They found the results of the research very promising and their materials showed similar mechanical properties to commercial buoys, simultaneously decreasing the ecological footprint, by incorporating waste rubber. Gayathri et al. [18] found out that the incorporation of ground tire rubber into polyurethane matrix caused enhancement in static mechanical properties and thermal stability measured by thermogravimetric analysis. Rubber-filled polyurethane foams showed also beneficial properties as acoustic insulation. Zhang et al. [19] also investigated the acoustic absorption properties of polyurethane foam compositions with GTR. They claimed that the incorporation of waste rubber into the PUF matrix could significantly enhance the insulation properties of the prepared foams in a very environmentally friendly way.

In all works mentioned above, there has been noticed disruption of cellular structure of polyurethane foams associated with the addition of ground tire rubber, which may be responsible for the enhancement of the mechanical and insulation properties of the resulting materials.

The main purpose of the presented work is the characterization of basic physical, mechanical and thermal properties of the polyurethane foams filled with untreated and thermo-mechanically reclaimed (using a co-rotating twin screw extruder and auto-thermal conditions) ground tire rubber. The influence of the type and amount of added ground tire rubber on the properties of flexible polyurethane foam was determined. In present literature, there is very little information about the incorporation of reclaimed GTR into polyurethanes [19]. In the presented research work, a reclamation process was performed using a corotating twin screw extruder, which provides continuity of the process. In most cases, the reclaiming/devulcanization of ground tire rubber is performed in a periodical manner using mills.

\section{Experimental}

\section{Materials}

Flexible polyurethane foams were synthesized from polyether polyols with trade names Rokopol M1170 (tri-functional copolymer of ethylene oxide, propylene oxide and glycerol) and Rokopol F3000 (tri-functional copolymer of propylene oxide based and glycerol). Both Rokopols were acquired from PCC Rokita S.A. (Poland) and recommended for the production of flexible polyurethane foams. The density of Rokopol M1170 at $25^{\circ} \mathrm{C}$ equals $1.09 \mathrm{~g} / \mathrm{cm}^{3}$ and its hydroxyl number has the value of $33 \mathrm{mg} \mathrm{KOH} / \mathrm{g}$ of resin. The viscosity at $25^{\circ} \mathrm{C}$ equals $1.2-1.5 \mathrm{~Pa}$ s. Its average molecular weight equals 5,000 g/mol. Rokopol F3000 is characterized by density at $25{ }^{\circ} \mathrm{C}$ of $1.01 \mathrm{~g} / \mathrm{cm}^{3}$ and by hydroxyl number of $56 \mathrm{mg} \mathrm{KOH} / \mathrm{g}$ of resin. Its viscosity at $25^{\circ} \mathrm{C}$ and average molecular weight equal $0.46-0.52 \mathrm{~Pa} \mathrm{~s}$ and 3,000 g/mol, respectively.

Isocyanate used in the reaction was $4,4^{\prime}$-methylene diphenyl diisocyanate (MDI) and it was characterized by $32 \%$ content of NCO groups (Borsdochem, Hungary). A $33 \%$ wt solution of 1,4-diazabicyclo[2.2.2] octane in ethylene glycol (DABCO 33LV), tin(II) 2-ethylhexanoate $\left(\mathrm{Sn}(\mathrm{Oct})_{2}\right)$ and sodium acetate $(\mathrm{NaOAc})$ were applied as catalysts. All catalysts were purchased from Sigma Aldrich. Niax Silicone SR-393 (Momentive, Czech Republic) was used as a silicon-based surfactant. Distilled water served as a chemical blowing agent. All chemicals were used as received. The foams were filled with a ground tire rubber with grain size $0.4 \mathrm{~mm}$ (R-recyclate) and a thermo-mechanically reclaimed ground tire rubber (D-devulcanize). The ground tire rubber was obtained from GrupaRecykl S.A. (Poland). The auto-thermal reclamation of the ground tire rubber was performed using co-rotating twin screw extruder EHP $2 \times 20$ from Zamak (Poland), with the screw configuration presented in Fig. 1. The rotating speed of screws was $300 \mathrm{~min}^{-1}$, while the yield of the 


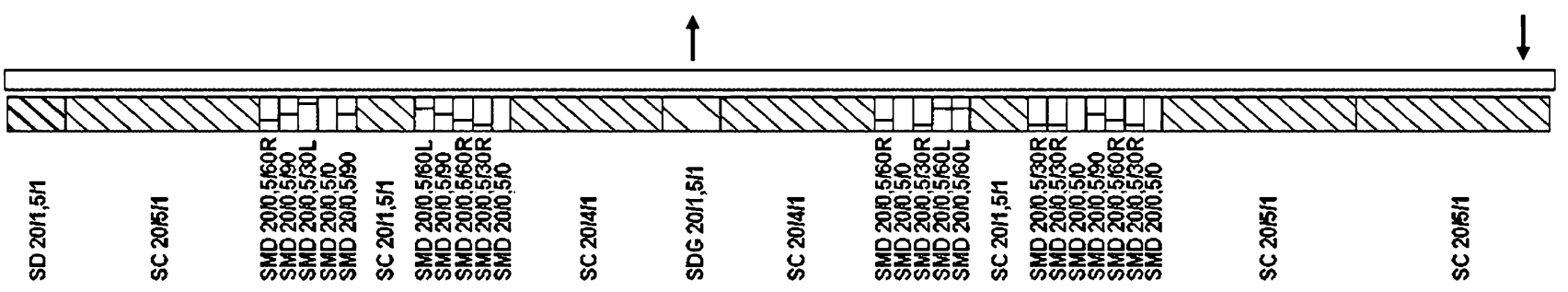

Fig. 1 Screw configuration used during ground tire rubber thermo-mechanical reclaiming. ( $S M D$ kneading element, $S C$, $S D$ and $S D G$ types of conveying elements. The segments were named according to Zamak Mercator specification)

process was $1.92 \mathrm{~kg} / \mathrm{h}$. To create auto-thermal conditions of reclamation, during initiation of the process, the cylinder of plasticizing unit was heated to $60{ }^{\circ} \mathrm{C}$, then after the stabilization of the process (stabilization of screw torque value) the heaters were turned off. The process of reclamation of the ground tire rubber in auto-thermal conditions has been described in a more detailed way in patent application [20]. Among the advantages of auto-thermal reclamation the following should be mentioned: intensification of shear forces acting on ground tire rubber, limitation of secondary crosslinking, reduction of energetic costs and reduction of the amount of gases generated during reclamation.

Foam synthesis

The flexible polyurethane foams were produced on a laboratory scale by a single step method from a two-component (A and $\mathrm{B}$ ) system with the ratio of isocyanate groups to hydroxyl groups $(\mathrm{NCO} / \mathrm{OH})$ equal to one. The component A (polyol mixture) consisting of the proper amounts of polyethers Rokopol M1170 and Rokopol F3000 (70:30), catalysts, surfactant, distilled water and filler in case of modified foams was weighed and placed in a $500 \mathrm{~mL}$ polypropylene cup. Next, the polyol mixture was homogenized with a mechanical stirrer at $1,800 \mathrm{rpm}$ for $60 \mathrm{~s}$. Such prepared component $\mathrm{A}$ was mixed with component $\mathrm{B}(\mathrm{MDI})$ at a predetermined mass ratio and stirred at 3,000 rpm for $10 \mathrm{~s}$. The resulting reaction mixture was poured into a closed metal mold of dimensions $100 \times 50 \times 40 \mathrm{~mm}$. After demolding, the obtained PUF samples were kept at $60{ }^{\circ} \mathrm{C}$ for $24 \mathrm{~h}$ and then seasoned at room temperature for $24 \mathrm{~h}$. Table 1 contains the details of foam formulations.

\section{Characterization}

After seasoning, the properties of the produced foams were determined according to standard procedures. In accordance with PN-EN ISO 845: 2000, the apparent density of PUF samples was calculated as a ratio of the sample weight to the sample volume. The volumes of cube-shaped samples were measured with a slide caliper with an accuracy
Table 1 Foam formulations

\begin{tabular}{llll}
\hline Weight of a chemical, pbw & \multicolumn{3}{l}{ Foam symbol } \\
\cline { 2 - 4 } & $P_{0}$ & $P_{\mathrm{R} 10 / \mathrm{D} 10}$ & $P_{\mathrm{R} 30 / \mathrm{D} 30}$ \\
\hline Rokopol M1170 & 60.0 & 54.0 & 42.3 \\
Rokopol F3000 & 25.0 & 22.5 & 17.6 \\
DABCO & 0.09 & 0.08 & 0.06 \\
$\mathrm{Sn}(\text { Oct })_{2}$ & 0.06 & 0.05 & 0.04 \\
NaOAc & 0.06 & 0.05 & 0.04 \\
SR393 & 0.3 & 0.3 & 0.2 \\
Water & 0.7 & 0.6 & 0.5 \\
Isocyanate & 13.9 & 12.5 & 9.7 \\
Filler & 0 & 10 & 30 \\
Isocyanate index & 1 & 1 & 1 \\
\hline
\end{tabular}

of $0.1 \mathrm{~mm}$. The samples were weighed using an electronic analytical balance with an accuracy of $0.1 \mathrm{mg}$.

The swelling degree of resulting foams $(0.2 \mathrm{~g}$ samples) was determined by equilibrium swelling in toluene (room temperature, $72 \mathrm{~h}$ ). The swollen samples were dried with a filter paper and weighed. The methodology used in this study for determination of PU foam swelling degree has been previously described in literature [21, 22].The swelling degree was calculated in accordance with Eq. (1):

$Q=\frac{m_{\mathrm{t}}-m_{\mathrm{o}}}{m_{\mathrm{o}}} \times 100 \%$

where: $Q$ is swelling degree; $m_{\mathrm{t}}$ mass of sample after $72 \mathrm{~h}$; $m_{\mathrm{o}}$ initial mass of sample.

The sol fraction for each sample was calculated in accordance with Eq. (2):

Sol fraction $=\frac{W_{1}-W_{2}}{W_{1}} \times 100 \%$

where: $W_{1}$ is the dry weight before extraction; $W_{2}$ is the dry weight of the sample after extraction.

The compressive strength of PUF samples was estimated in accordance with PN-EN ISO 604:2006. The samples of cubic shape and $50 \times 50 \times 50 \mathrm{~mm}$ size were measured 


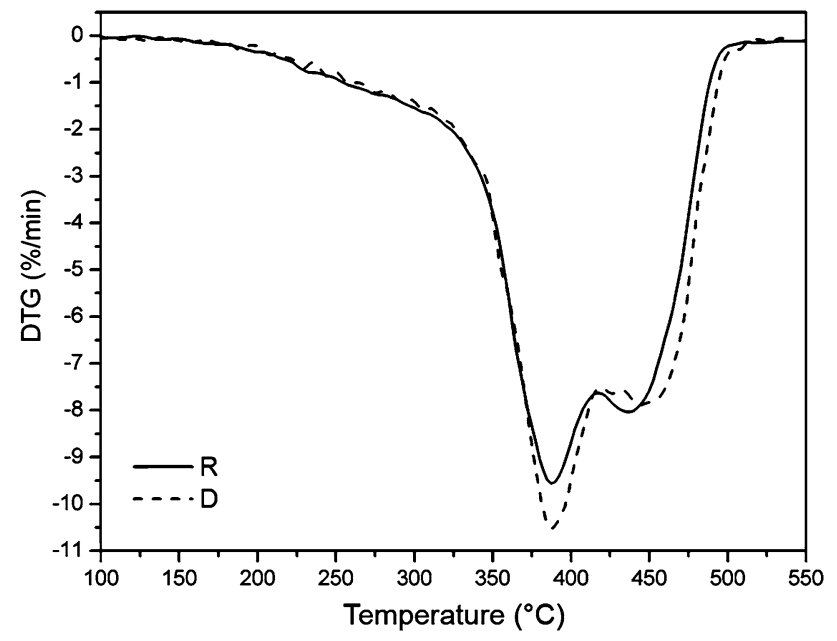

Fig. 2 Differential thermogravimetric curves as a function of temperature for untreated $(R)$ and thermo-mechanically reclaimed $(D)$ ground tire rubber

with a slide caliper with an accuracy of $0.1 \mathrm{~mm}$. The compression test was performed on a Zwick/Roell tensile tester at a constant speed of $10 \mathrm{~mm} / \mathrm{min}$ to reach a $30 \%$ deformation.

The dynamic mechanical analysis was performed using DMA Q800 TA Instruments apparatus. The samples were analyzed in uniaxial bending mode, with a frequency of $1 \mathrm{~Hz}$. Measurements were performed for the temperature range from -80 to $220{ }^{\circ} \mathrm{C}$, with heating rate $4{ }^{\circ} \mathrm{C} /$ min. The samples were beam shaped, with dimensions of $40 \times 10 \times 4 \mathrm{~mm}$.

Differential scanning calorimetry (DSC) was performed on a NETZSCH DSC 204 F1 Phoenix apparatus under nitrogen atmosphere in the temperature range from -85 to $250{ }^{\circ} \mathrm{C}$, and at a heating rate of $10^{\circ} \mathrm{C} / \mathrm{min}$.

The thermogravimetric analysis (TGA) was performed on a NETZSCH TG 209 apparatus using $5 \mathrm{mg}$ samples in the temperature range $100-600{ }^{\circ} \mathrm{C}$ and under argon atmosphere, at a heating rate of $20^{\circ} \mathrm{C} / \mathrm{min}$.

The morphology of PUR/GTR foams was characterized with Philips-FEI XL 30 environmental scanning electron microscope (ESEM) using an acceleration of $20 \mathrm{kV}$. The samples were cut to the required dimensions at ambient temperature. The SEM images were analyzed with ImageJ computer software to measure the size of cells.

\section{Results and discussion}

Auto-thermal reclamation of GTR

The results of thermogravimetric analysis of neat and thermo-mechanically reclaimed ground tire rubber are presented in Fig. 2. Two peaks from DTG curves are related to the temperatures of maximum rate of thermal degradation of natural rubber $\left(T_{\max 1}\right)$ and styrene-butadiene rubber $\left(T_{\max 2}\right)$. Those rubbers are the main compounds used in car tires manufacturing.

The obtained results confirmed changes in the chemical structure of GTR during reclamation at $60{ }^{\circ} \mathrm{C}$. High shear forces acting on GTR during low temperature extrusion caused scission of sulfide bonds. Cross-link density decrease corresponded to the lower thermal stability of reclaimed GTR [23].

Structural, physical and mechanical properties

The resulting foam properties are summarized in Table 2 . Figure 3 shows the morphology of flexible polyurethane foams and Fig. 4 shows the results of dynamic mechanical analysis.

The presented SEM images of the samples and values of cell size indicate significant differences in the morphology between foams containing neat and thermo-mechanically reclaimed ground tire rubber. Higher values of cell diameters for $P_{\mathrm{D}}$ foams (foams containing reclaimed GTR) are related to the increased foamability of the reaction mixtures, whic is associated with the introduction of different functional groups into the GTR surface due to the oxidation of the material during the reclamation process [24]. Regardless of GTR type (unmodified/thermo-mechanically reclaimed), lower values of cell size observed in case of $P_{30}$ foams (foams with $30 \mathrm{pbw}$ of filler) compared to $P_{10}$ samples (foams with $10 \mathrm{pbw}$ of filler) are associated with the increased viscosity of the reaction mixture caused by addition of rubber fillers.
Table 2 Comparison of foam properties

\begin{tabular}{lllll}
\hline Sample & $\begin{array}{l}\text { Apparent } \\
\text { density, } \mathrm{kg} / \mathrm{m}^{3}\end{array}$ & $\begin{array}{l}\text { Compressive strength at } \\
30 \% \text { deformation, } \mathrm{kPa}\end{array}$ & $\begin{array}{l}\text { Degree of } \\
\text { swelling }\end{array}$ & $\begin{array}{l}\text { Glass transition } \\
\text { temperature, }{ }^{\circ} \mathrm{C}\end{array}$ \\
\hline$P_{0}$ & 290 & $20.9 \pm 1.0$ & $134.85 \pm 2.77$ & -36.6 \\
$P_{\mathrm{R} 10}$ & 299 & $21.8 \pm 0.6$ & $133.70 \pm 3.56$ & -32.9 \\
$P_{\mathrm{R} 30}$ & 308 & $22.5 \pm 0.3$ & $108.47 \pm 2.21$ & -33.4 \\
$P_{\mathrm{D} 10}$ & 316 & $13.0 \pm 0.9$ & $137.18 \pm 1.75$ & -32.5 \\
$P_{\mathrm{D} 30}$ & 315 & $15.7 \pm 0.2$ & $106.14 \pm 3.14$ & -33.5 \\
\hline
\end{tabular}


Fig. 3 SEM images of: a reference foam, $\mathbf{b} P_{\mathrm{R} 10}$ foam, c $P_{\mathrm{R} 30}$ foam, d $P_{\mathrm{D} 10}$ foam, e $P_{\mathrm{D} 30}$ foam
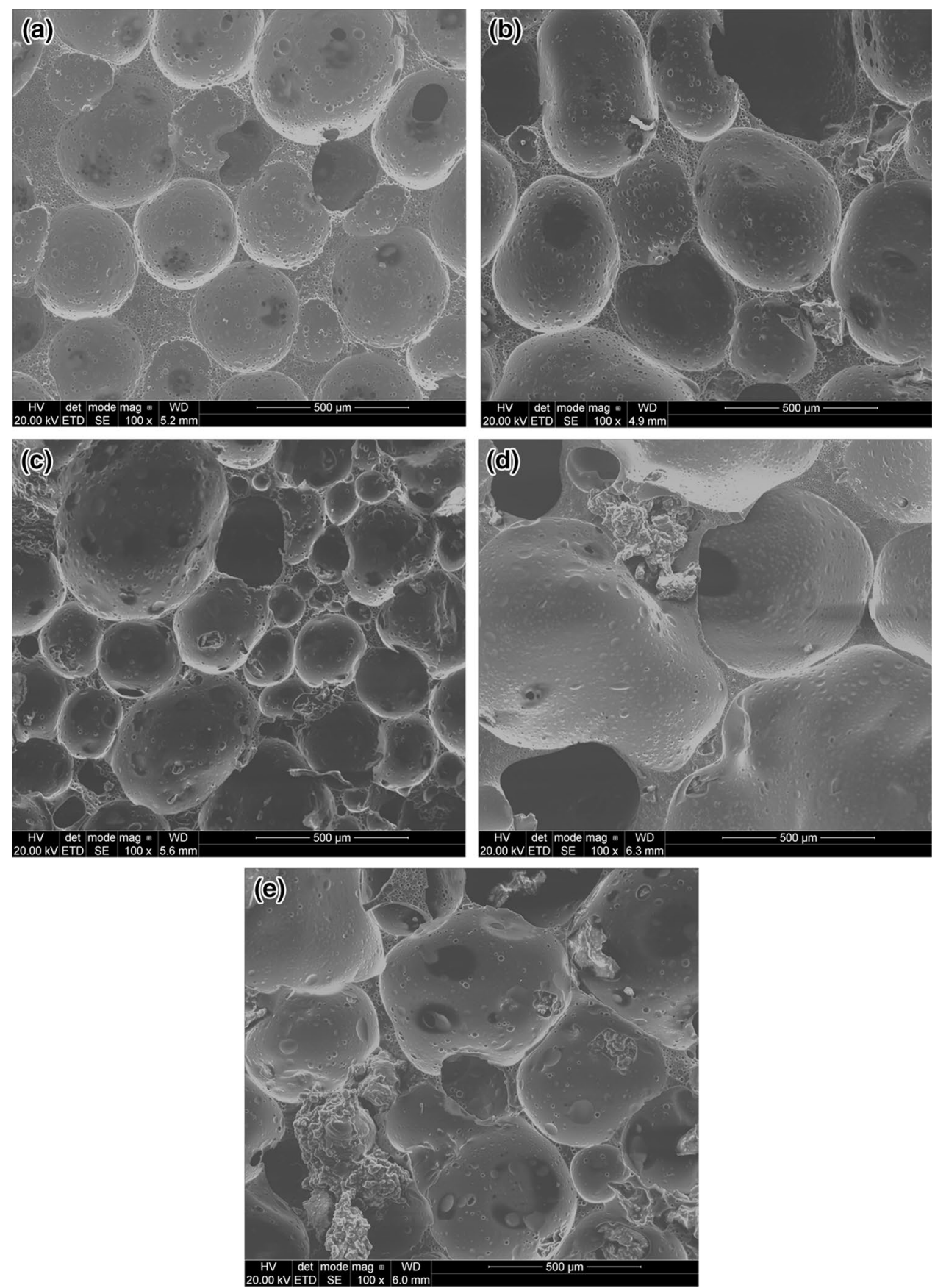

The incorporation of both types of ground tire rubber increased the values of the apparent density of the material. However, this effect was stronger in case of thermomechanically reclaimed GTR particles, which was related to the different influence of both types of GTR on the structure of pores in the prepared foams. Functional groups present on the surface of devulcanized GTR had reacted with the isocyanate during polymerization, which resulted in enhanced interactions between the matrix and filler. Simultaneously, decreased volumetric expansion of foam resulted in increased apparent density.
The mechanical properties of polyurethane foams are significantly related to their apparent density; an increase in the apparent density causes a corresponding increase in the compressive strength [12]. However, increase of compressive strength was observed only for the materials containing neat GTR. No such effect was observed for the foams modified with thermo-mechanically reclaimed ground tire rubber, which was related to the deterioration of polymer matrix strength due to the filler-matrix interactions and to the devulcanization of rubber, occurring during its reclamation, which caused breakage of S-S 


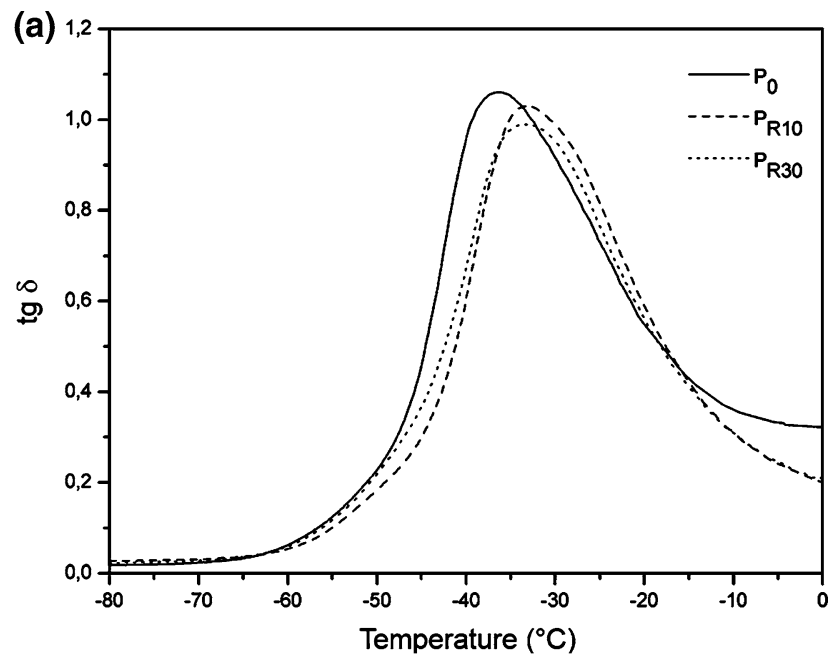

(b)

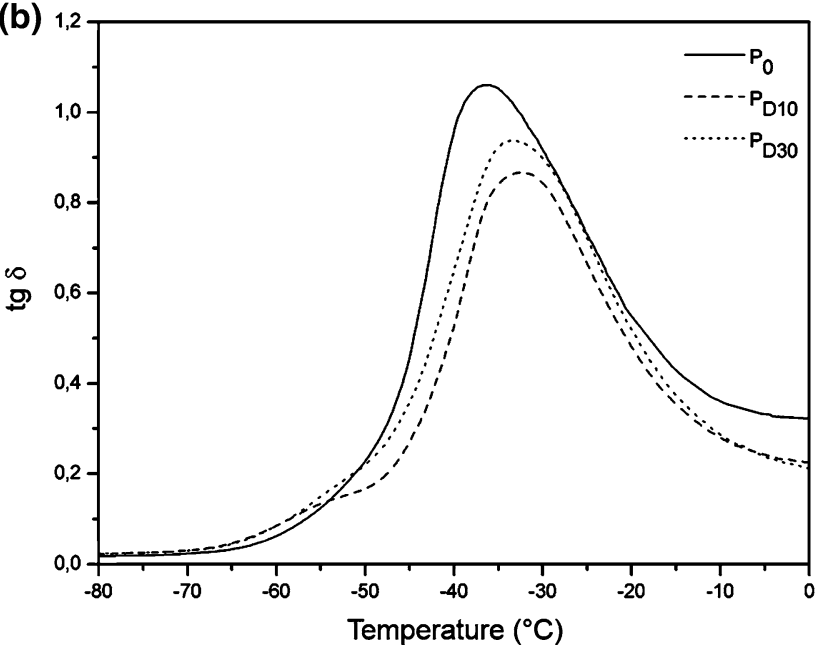

Fig. 4 Loss tangent of the prepared polyurethane foams with untreated $(R)$ and thermo-mechanically reclaimed $(D)$ ground tire rubber

bonds responsible for the mechanical properties of vulcanized rubber.

The differences in values of swelling degree and sol fraction between the foams containing the same amount of unmodified and thermo-mechanically reclaimed ground tire rubber are related to the different amounts of $\mathrm{S}-\mathrm{S}$ bonds in both the fillers and different interactions of fillers with the PU matrix. As mentioned before, the reclamation of ground tire rubber decreased its content of $\mathrm{S}-\mathrm{S}$ bonds, which is equivalent with lower cross-link density. Other phenomena, associated with the reclamation of rubber, are oxidation of the material and creation of different functional groups on the surface of rubber particles. These groups are able to react with isocyanates present during the synthesis of polyurethane foam, which leads to specific interactions between the fillers and matrix. Another reason for the decrease in compressive strength is the reaction of isocyanate with the functional groups of reclaimed ground tire rubber, by which some hydroxyl end groups remain unreacted and the polyurethane matrix becomes weaker.

The dynamic mechanical analysis was performed to determine the glass transition temperature $\left(T_{\mathrm{g}}\right)$ of the obtained polyurethane foams, which was assigned to the maximum of loss tangent as a function of temperature. Determination of $T_{\mathrm{g}}$ using loss tangent enables elimination of measurement inaccuracies related to sample dimensions. For each investigated sample, only one peak is observed because of similar values of loss tangents of polyurethane matrix and ground tire rubber. All modifications caused stiffening of polyurethane foam, leading to higher glass transition temperature in comparison to the reference sample. The $T_{\mathrm{g}}$ observed for unmodified foam was $-36.6{ }^{\circ} \mathrm{C}$, while incorporation of ground tire rubber caused its shift into range from -33.5 to $-32.5{ }^{\circ} \mathrm{C}$. It was observed that higher content of GTR in PUR/GTR composites caused small decrease of glass transition temperature (ca. $0.5-1{ }^{\circ} \mathrm{C}$ ). This phenomenon is related to reaction of isocyanates with the functional groups of reclaimed ground tire rubber. The products of this side reaction may act like the plasticizers of ground tire rubber.

It was unexpected that only one glass transition temperature was observed. This is due to overlapping of glass transition temperatures from polyurethane foam and ground tire rubber, which was confirmed by similar results of differential scanning calorimetry $\left(T_{\mathrm{g}}\right.$ for PUR around $-52.0^{\circ} \mathrm{C}$ and $T_{\mathrm{g}}$ for both types of GTR around $-57.5^{\circ} \mathrm{C}$, please see "Thermal properties"). It is well known that rubber particles with size around $400 \mu \mathrm{m}$ are too big to affect the mobility of polymer chains within the matrix. However, the obtained results indicate that active groups presented in the surface of ground tire rubber/reclaimed GTR may act as linkages between polyurethane chains, affecting the $T_{\mathrm{g}}$ of PUR/GTR composite foams [25]. Moreover, addition of rubber particles to polyurethane foam causes disruption of cellular structure, which has been already proved in different research works [17-19].

Table 3 Glass transition temperatures and changes in heat capacity of the produced foams

\begin{tabular}{llllll}
\hline Sample & $T_{\mathrm{g} 1},{ }^{\circ} \mathrm{C}$ & $T_{\mathrm{g} 2},{ }^{\circ} \mathrm{C}$ & $\mathrm{Cp}_{1}, \mathrm{~J} /(\mathrm{g} . \mathrm{K})$ & $\mathrm{Cp}_{2}, \mathrm{~J} /(\mathrm{g} . \mathrm{K})$ & $\mathrm{Cp}_{2}{ }^{\prime}, \mathrm{J} /(\mathrm{g} . \mathrm{K})$ \\
\hline$R$ & -57.3 & - & 0.018 & - & - \\
$D$ & -57.6 & - & 0.032 & - & - \\
$P_{0}$ & - & -52.0 & - & 0.565 & 0.565 \\
$P_{\mathrm{R} 10}$ & -62.0 & -49.3 & 0.107 & 0.327 & 0.363 \\
$P_{\mathrm{R} 30}$ & -62.2 & -49.3 & 0.076 & 0.214 & 0.306 \\
$P_{\mathrm{D} 10}$ & -63.4 & -50.4 & 0.055 & 0.404 & 0.449 \\
$P_{\mathrm{D} 30}$ & -63.2 & -49.6 & 0.044 & 0.229 & 0.327 \\
\hline
\end{tabular}




\section{Thermal properties}

The results of DSC analysis are presented in Table 3 and Fig. 5 as thermograms. For each thermogram for the modified foams, two glass transitions can be observed, one related to ground tire rubber $\left(T_{\mathrm{g} 1}\right)$ and the other to the polyurethane matrix $\left(T_{\mathrm{g} 2}\right)$. The glass transition temperature of the polyurethane matrix increased with addition of fillers, which was associated with the lower mobility of polymer chains in the structure due to interaction between polyurethane and ground tire rubber particles. On the other hand, the glass transition temperature $\left(T_{\mathrm{g} 1}\right)$ associated with GTR decreases from around $-57.5{ }^{\circ} \mathrm{C}$ for neat GTR/reclaimed GTR to -62 to $-63{ }^{\circ} \mathrm{C}$ for the PUR/GTR foam composite with $30 \mathrm{pbw}$ of GTR. These results suggest that some of the
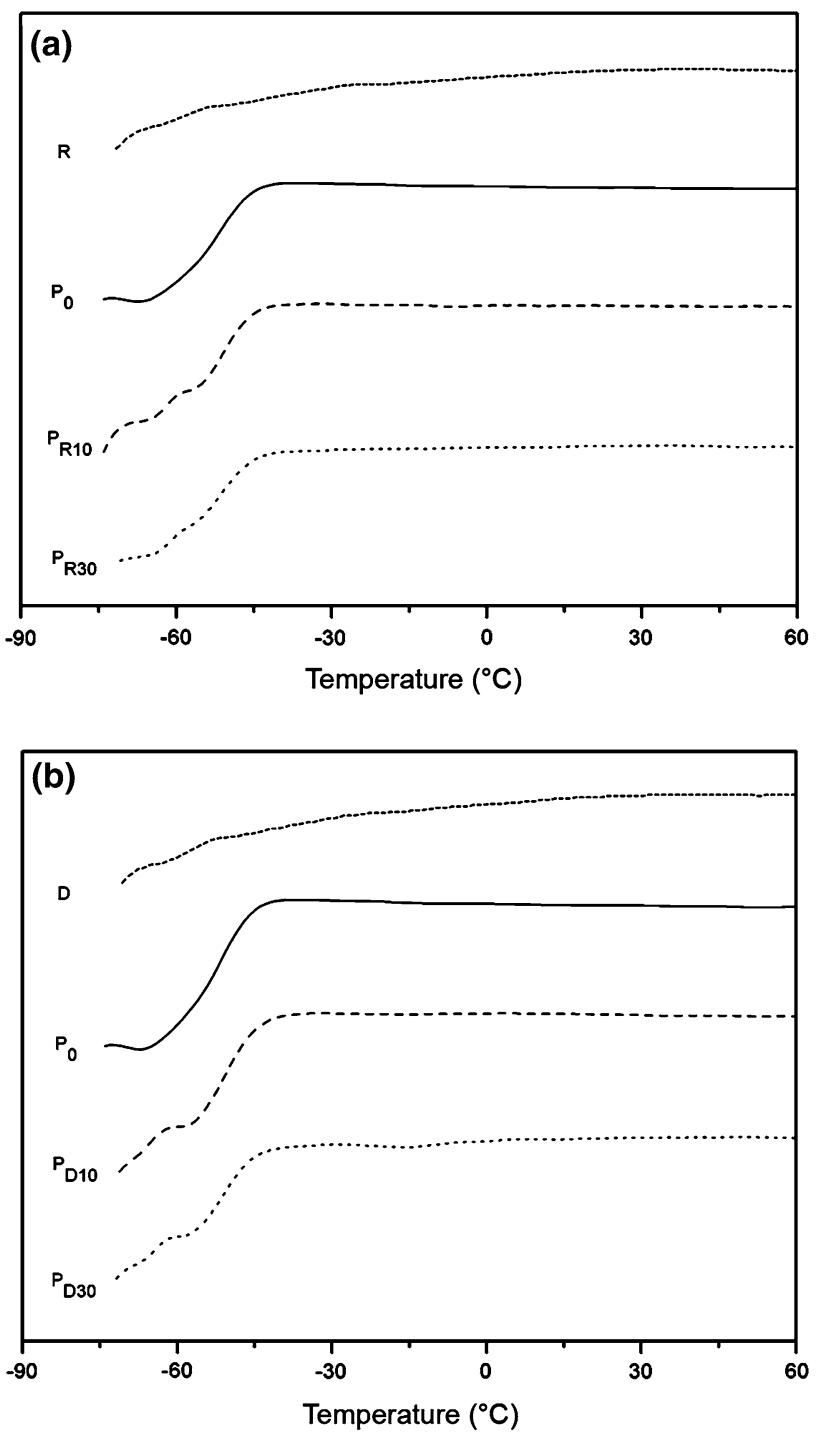

Fig. 5 Thermograms of the prepared polyurethane foams with untreated $(R)$ and thermo-mechanically reclaimed $(D)$ ground tire rubber unreacted hydroxyl end groups may act like the plasticizer of ground tire rubber, which confirms the results of DMA.

The glass transition occurs as a step increase in the heat capacity $\left(C_{\mathrm{p}}\right)$ of the sample during heating, which is due to an enhancement of molecular motion in the polymer [26, 27]. In the case of reference foam $P_{0}$, the value of $\Delta C_{\mathrm{p}}$ related to the glass transition of the polyurethane matrix was significantly higher compared to the filled foams, which can be related to different amounts of polyurethane in each sample due to the incorporation of GTR particles. However, values calculated for the actual content of $\mathrm{PU}\left(\Delta C_{\mathrm{p} 2}\right)$ still decrease with the addition of filler to neat polyurethane, which is related to the higher mobility of the polymer chains not affected by the presence of rubber particles [28]. These results confirm that some low molecular weight products were formed during the reaction between the isocyanate group and oxygen containing groups present on GTR surface.

The mechanism of thermal degradation of polyurethane foams is often described as being very complex. The thermal degradation of polyurethanes occurs in two main stages. The first stage is related to the degradation of the hard segments (HS), which occurs as a consequence of the relatively low thermal stability of the urethane groups. This step involves dissociation of the polyol and isocyanate components, which is followed by the thermal decomposition leading to the formation of amines, carbon dioxide and other low molecular weight compounds [27, 29]. The second stage has been associated with the soft segment (SS) decomposition, which is relatively slower than the first step [30-32]. Obviously, the rate of the second step depends very strongly on the soft segments' structure and their arrangement. Gomes Lage and Kawano in their works suggested that mass loss in every stage of decomposition could be related to the amount of hard and soft segments in polyurethane [33]. Using this approximation, hardly no HS has been observed in the prepared foams, which is related to the foams' formulations.

The results of thermogravimetric analysis are shown in Fig. 6 and Table 4. The thermal degradation measured by the initial degradation temperature $\left(T_{\text {init }}\right)$, corresponding to $2 \%$ mass loss, was, in most cases, slightly retarded by incorporation of rubber fillers. The incorporation of $30 \mathrm{wt} \%$ of regenerated ground tire rubber increased $T_{\text {init }}$ by $14{ }^{\circ} \mathrm{C}$. Incorporation of rubber fillers has, however, a big impact on the weight percentage of residue at $510{ }^{\circ} \mathrm{C}$ $\left(\mathrm{wt}_{\mathrm{R}}^{510}\right)$ of the prepared foams. Addition of $30 \mathrm{wt} \%$ of used fillers increased this residue over two times. Increase of $\mathrm{wt}_{\mathrm{R}}^{510}$ for modified foams is related to very high $\mathrm{wt}_{\mathrm{R}}^{510}$ of used modifiers exceeding $37 \%$, caused by the presence of carbon black in rubber fillers.

As mentioned before, the formulations of prepared polyurethane foams result in lack of hard segments in 

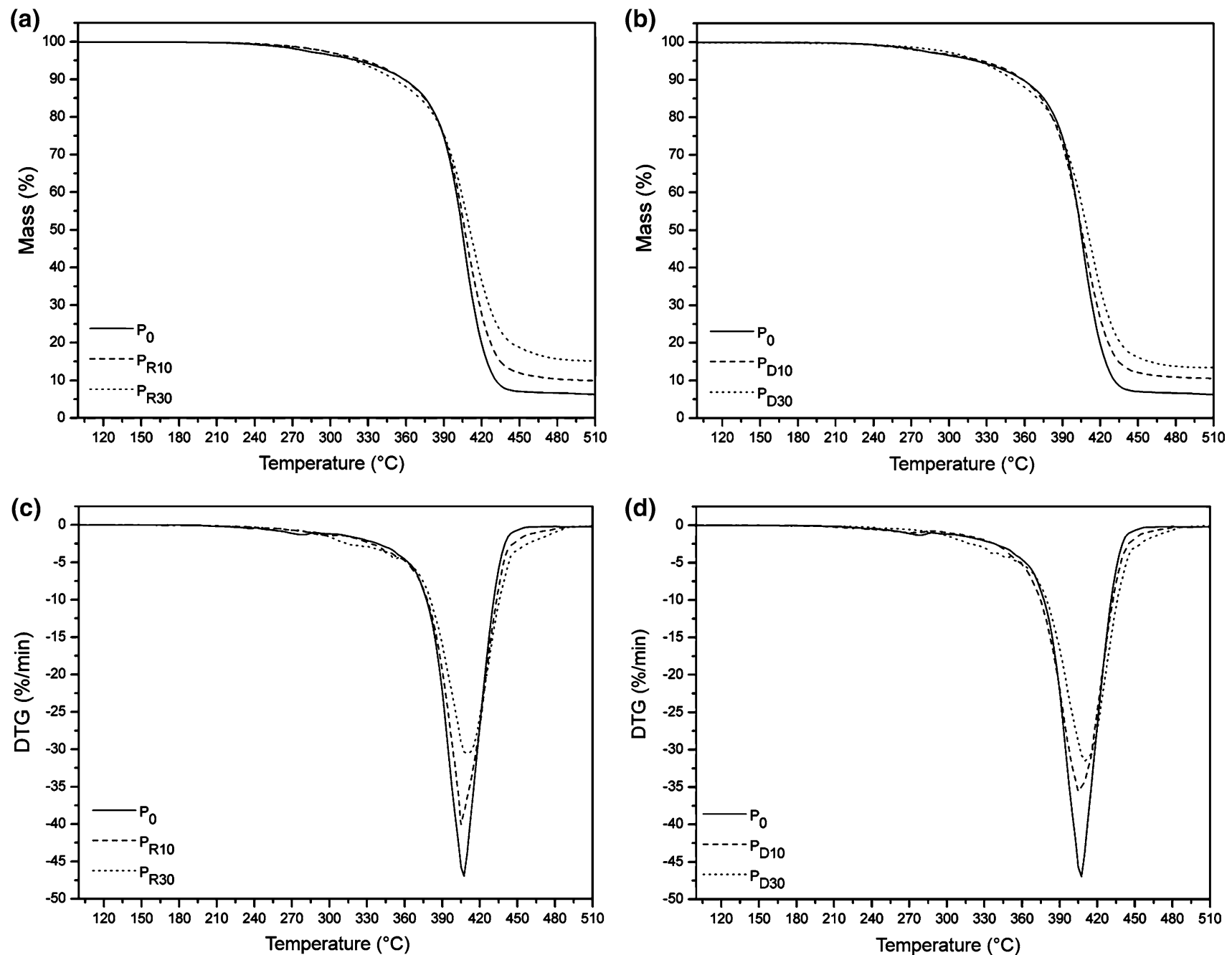

Fig. 6 Mass loss and differential thermogravimetric curves as a function of temperature for polyurethane foams filled with ground tire rubber

Table 4 Characteristics of thermal degradation of composite foams

\begin{tabular}{lllllll}
\hline Sample & \multicolumn{2}{l}{ Mass loss, $\%$} & & $\mathrm{wt}_{\mathrm{R}}^{510}, \%$ & $T_{\max },{ }^{\circ} \mathrm{C}$ \\
\cline { 2 - 4 } & 2 & 5 & 10 & 50 & & \\
& \multicolumn{2}{l}{ Temperature, ${ }^{\circ} \mathrm{C}$} & & & & \\
\hline$R$ & 255.7 & 302.6 & 348.1 & 453.1 & 41.52 & 388.8 \\
$D$ & 249.4 & 301.5 & 349.0 & 450.2 & 37.97 & 387.8 \\
$P_{0}$ & 273.9 & 321.6 & 358.4 & 404.5 & 6.27 & 406.9 \\
$P_{\mathrm{R} 10}$ & 287.3 & 327.3 & 358.1 & 406.6 & 9.92 & 405.5 \\
$P_{\mathrm{R} 30}$ & 286.4 & 319.2 & 350.9 & 410.6 & 15.18 & 410.1 \\
$P_{\mathrm{D} 10}$ & 271.2 & 326.2 & 358.7 & 405.2 & 10.52 & 406.0 \\
$P_{\mathrm{D} 30}$ & 287.9 & 322.7 & 351.2 & 409.8 & 13.41 & 410.1 \\
\hline
\end{tabular}

their structure. This can be easily seen on the differential thermogravimetric curves, where generally only one peak is observed for each sample. The temperature of the fastest degradation $\left(T_{\max }\right)$ of the reference foam was $406.9^{\circ} \mathrm{C}$. Slight differences in the course of DTG curves between neat and modified PU foams are observed in the temperature range from 250 to $360{ }^{\circ} \mathrm{C}$, which can be associated with the chemical interactions between functional groups present on the surface of GTR particles and isocyanate used during synthesis. This is also a reason for the inhibition of 
thermal degradation in the initial phase. However, incorporation of rubber fillers did not have any significant influence on further stages of thermal degradation, which can be seen on the DTG curves and values of degradation temperatures related to 10 and $50 \%$ mass loss.

\section{Conclusions}

The presented research work confirmed that incorporation of ground tire rubber into polyurethane foams has a significant and positive influence on the thermal stability and compressive strength of the resulting material, simultaneously decreasing their ecological footprint, which is related to the use of waste materials.

The presented results confirmed the reaction between the isocyanate group and active groups present on the surface of rubber particles on the GTR surface, which has significant influence on the microstructure and properties of polyurethane/ground tire rubber composite foams.

It was observed that, regardless of the GTR type, lower values of cell size were observed in case of PUR/GTR composite foam with $30 \mathrm{pbw}$ of GTR compared to the samples with $10 \mathrm{pbw}$ of GTR. This phenomenon is associated with an increased viscosity of the reaction mixture caused by addition of rubber fillers.

Addition of rubber particles to the polymer matrix increased the apparent density of the material; however, it was not always associated with enhancement of compressive strength. In case of thermo-mechanically reclaimed GTR no reinforcement effect was observed, due to changes in rubber structure during reclamation. The devulcanization of rubber occurring during reclamation causes breaking of S-S bonds responsible for the mechanical properties of rubber and leads to creation of different oxygen functional groups on the surface of the material.

Due to the presence of GTR particles, the mobility of polymer chains was considerably decreased, which resulted in an increase of the glass transition temperature of polyurethane matrix, confirmed, both, by the dynamic mechanical analysis and differential scanning calorimetry. The $T_{\mathrm{g}}$ values increased even by $4{ }^{\circ} \mathrm{C}$ with addition of ground tire rubber.

The incorporation of rubber waste into the polyurethane matrix enhanced the thermal stability of the resulting foams. The initial degradation temperature and weight percentage of the residue at $510{ }^{\circ} \mathrm{C}$ significantly increased with addition of GTR, which was related to the presence of carbon black in the used fillers.

Future research related to modification of polyurethane foams with rubber waste will be focused on the interactions between GTR particles and isocyanates and on incorporation of other waste materials or raw materials from renewable resources, such as vegetable oils or lignin, to further reduce the ecological footprint of the resulting plastics.

Open Access This article is distributed under the terms of the Creative Commons Attribution License which permits any use, distribution, and reproduction in any medium, provided the original author(s) and the source are credited.

\section{References}

1. Lo Presti D (2013) Recycled tyre rubber modified bitumens for road asphalt mixtures: a literature review. Constr Build Mater 49:863-881

2. Amari T, Themelis NJ, Wernik IK (1999) Resource recovery from used rubber tires. Resour Pol 25:179-188

3. Formela K, Haponiuk JT (2014) Curing characteristics, mechanical properties and morphology of butyl rubber filled with ground tire rubber (GTR). Iran Polym J 23:185-194

4. Nabil H, Ismail H, Azura AR (2014) Properties of natural rubber/ recycled ethylene-propylene-diene rubber blends prepared using various vulcanizing systems. Iran Polym J 23:37-45

5. Wu W, Zhang J (2012) Preparation and characterization of environment friendly used rubber powder modified pulp sediments composites. Iran Polym J 21:763-769

6. Karger-Kocsis J, Mészáros L, Bárány T (2013) Ground tire rubber (GTR) in thermoplastics, thermosets, and rubbers. J Mater Sci 48:1-38

7. Dong Q, Huang B, Shu X (2013) Rubber modified concrete improved by chemically active coating and silane coupling agent. Constr Build Mater 48:116-123

8. López-Moro FJ, Moro MC, Hernández-Olivares F, WitoszekSchultz B, Alonso-Fernández M (2013) Microscopic analysis of the interaction between crumb rubber and bitumen in asphalt mixtures using the dry process. Constr Build Mater 48:691-699

9. Mortazavi SB, Rasoulzadeh Y, Yousefi AA, Khavanin A (2010) Properties of modified bitumen obtained from vacuum bottom by adding recycled waste polymers and natural bitumen. Iran Polym J 19:197-205

10. Formela K, Cysewska M (2014) Efficiency of thermomechanical reclaiming of ground tire rubber conducted in counter-rotating and co-rotating twin screw extruder. Polimery 3:231-238

11. Mangili I, Collina E, Anzano M, Pitea D, Lasagni M (2014) Characterization and supercritical $\mathrm{CO}_{2}$ devulcanization of cryoground tire rubber: influence of devulcanization process on reclaimed material. Polym Degrad Stabil 102:15-24

12. Bulent Koc A, Abdullah M (2014) Performance of a 4-cylinder diesel engine running on tire oil-biodiesel-diesel blend. Fuel Process Technol 118:264-269

13. Karger-Kocsis J (2013) Waste tyre rubber-what to do next? Express Polym Lett 7:406

14. Xin ZX, Zhang ZX, Pal K, Lu BX, Deng X, Lee SH, Kim JK (2009) Effects of formulation and processing parameters on the morphology of extruded polypropylene-(waste ground rubber tire powder) foams. J Vinyl Add Technol 15:266-274

15. Zhu J, Zhang X, Liang M, Lu C (2011) Enhancement of processability and foamability of ground tire rubber powder and LDPE blends through solid state shear milling. J Polym Res 18:533-539

16. Tian D, Zhang X, Zhu J, Lu C (2013) Morphology and physical properties of composite foams based on low-density polyethylene and ground tire rubber. J Vinyl Add Technol 19:105-112

17. Cachaço AG, Afonso MD, Pinto ML (2013) New applications for foam composites of polyurethane and recycled rubber. J Appl Polym Sci 129:2873-2881 
18. Gayathri R, Vasanthakumari R, Padmanabhan C (2013) Sound absorption, thermal and mechanical behavior of polyurethane foam modified with nano silica, nano clay and crumb rubber fillers. Int J Sci Eng Res 4:301-308

19. Zhang X, Lu Z, Tian D, Li H, Lu C (2013) Mechanochemical devulcanization of ground tire rubber and its application in acoustic absorbent polyurethane foamed composites. J Appl Polym Sci 127:4006-4014

20. Formela K, Haponiuk J (2014) Method of ground tire rubber modification. Pat. application PL P-407660

21. Campanella A, Bonnaillie LM, Wool RP (2009) Polyurethane foams from soy oil-based polyols. J Appl Polym Sci 112:2567-2578

22. Lei Y, Zhou S, Zou H, Liang M (2014) Effect of crosslinking density on resilient performance of low-resilience flexible polyurethane foams. Polym Eng Sci. doi:10.1002/pen.23888

23. Kleps T, Piaskiewicz M, Parasiewicz W (2000) The use of thermogravimetry in the study of rubber devulcanization. J Therm Anal Calorim 60:271-277

24. Zhang X, Tian D, Zhang W, Zhu J, Lu C (2013) Morphology, foaming rheology and physical properties of ethylene-propylene diene rubber/ground tire rubber (GTR) composite foams: effect of mechanochemical devulcanisation of GTR. Prog Rubber Plast Recycl Technol 29:81-98

25. Danach A, Sułkowski WW, Moczyński M, Radon A, Stelzer F, Jurga S (2004) Structural relaxation and morphology of the rubber-urethane composites. J Appl Polym Sci 94:1186-1193
26. Hatakeyama T, Quinn FX (1994) Thermal analysis: Fundamentals and applications to polymer science. Wiley, Chicester

27. Tanaka R, Hirose S, Hatakeyama H (2008) Preparation and characterization of polyurethane foams using a palm oil-based polyol. Bioresour Technol 99:3810-3816

28. Hatakeyama T, Asano Y, Hatakeyama H (2003) Mechanical and thermal properties of rigid polyurethane foams derived from sodium lignosulfonate mixed with diethylene-, triethylene- and polyethylene glycols. Macromol Symp 197:171-180

29. Somania KP, Kansaraa SS, Patel NK, Rakshit AK (2003) Castor oil based polyurethane adhesives for wood-to-wood bonding. Int J Adhes Adhes 23:269-275

30. Cervantes-Uc JM, Moo Espinosa JI, Cauich-Rodriguez JV, AvilaOrtega A, Vazquez-Torres H, Marcos-Fernandez A, San Roman J (2009) TGA/FTIR studies of segmented aliphatic polyurethanes and their nanocomposites prepared with commercial montmorillonites. Polym Degrad Stabil 94:1666-1677

31. Petrovic ZS, Zavargo Z, Flyn JH, Macknight WJ (1994) Thermal degradation of segmented polyurethanes. J Appl Polym Sci 51:1087-1095

32. Pawlik H, Prociak A (2012) Influence of palm oil-based polyol on the properties of flexible polyurethane foams. J Polym Environ $20: 438-445$

33. Gomes Lage L, Kawano Y (2001) Thermal degradation of biomedical polyurethanes-a kinetic study using high-resolution thermogravimetry. J Appl Polym Sci 79:910-919 